\title{
POLÍTICAS PÚBLICAS EDUCACIONAIS: APONTAMENTOS SOBRE O DIREITO SOCIAL DA QUALIDADE NA EDUCAÇÃO
}

\author{
PUBLIC POLICY EDUCATIONAL: NOTES ABOUT SOCIAL LAW OF QUALITY IN \\ EDUCATION
}

\author{
Cleia Simone Ferreira ${ }^{1}$ \\ Everton Neves dos Santos ${ }^{2}$
}

"Ninguém ignora tudo. Ninguém sabe tudo. Todos nós sabemos alguma coisa. Todos nós ignoramos alguma coisa. Por isso aprendemos sempre”. Paulo Freire

\section{RESUMO}

As Políticas Públicas Educacionais enquanto direcionadoras na construção de uma escola que oferece uma formação cidadã, foi o tema debatido neste artigo. O objetivo foi analisar a importância das Políticas Públicas Educacionais, para qualificar a educação pública no Brasil, ampliando a qualidade do ensino fundamental. Para o alcance do objetivo traçado foi desenvolvida uma pesquisa bibliográfica com análise qualitativa, a qual permitiu a construção de considerações finais, sem contudo, ousar o fechamento do assunto, que envolve-se num contexto de complexidade, necessitando o aporte do Direito. O estudo considerou na essência que a Constituição Federal de 1988, o Estatuto da Criança e do Adolescente promulgado em 1990 e a Lei de Diretrizes e Bases da Educação 9.394/1998, foram a base da construção do conceito de qualidade na educação enquanto direito social.

Palavras-chave: Qualidade na Educação - Estatuto da Criança e do Adolescente - Lei de Diretrizes e Bases da Educação - Constituição Federal.

\section{ABSTRACT}

The Public Policy Education direcionadoras while the construction of a school that offers a citizenship training, was the topic discussed in this article. The objective was to analyze the importance of Public Policy Education, to qualify for public education in Brazil, increasing the quality of basic education. To reach the objective outlined a literature research with qualitative analysis, which allowed the construction of final remarks, without, dare closure of the issue, which involves in a context of complexity, requiring the contribution of law was developed. The study considered the essence of the 1988 Federal Constitution, the Statute of Children and Adolescents promulgated in 1990 and the Law of Guidelines and Bases of Education 9.394/1998, were the basis for the construction of the concept of quality in education as a social right.

Keywords: Quality in Education - Statute of Children and Adolescents - Law of Guidelines and Bases of Education - Federal Constitution. 


\section{INTRODUÇÃO}

No decurso deste artigo, dentre os temas abordados três se despontam: as políticas públicas educacionais; a qualidade na educação com foco ao ensino fundamental e, a concepção de que a discussão aqui apresentada está diretamente relacionada ao direito social de todos os cidadãos.

Não há como construir uma sociedade efetivamente voltada para a cidadania, a ética e valores de família sem que a educação possa ser o alicerce que fecunda os pilares da dignidade. Assim, resta analisar os problemas que são vislumbrados na educação atual, com ênfase para o ensino fundamental, tratando inclusive do processo de ajustes e transformações que se iniciaram no Brasil com a alteração da Lei de Diretrizes e Bases da Educação Nacional - LDB ํo 9.394/1996 a partir das Leis Federais no $11.114 / 2005$ e $11.274 / 2006$.

Considera-se importante salientar que as mudanças vivenciadas nas últimas duas décadas na educação brasileira estão envoltas na evolução das LDBs e, especialmente, no uso de Políticas Públicas Educacionais voltadas para a construção de uma educação inclusiva, cidadã e de qualidade.

A proposta aqui apresentada teve como objetivo analisar a importância das Políticas Públicas Educacionais, para qualificar a educação pública no Brasil, ampliando a qualidade do ensino fundamental.

Para a realização do estudo foi utilizada uma pesquisa bibliográfica, com análise qualitativa em dados secundários, possibilitando a construção de conhecimentos acerca do tema Políticas Públicas Educacionais e a necessidade de uma perspectiva social para a construção de uma educação de qualidade.

A qualidade da educação aqui comentada não trata somente dos métodos e processos educacionais, mas especialmente, o direito a educação cidadã que deve ser assegurada a todas as pessoas como forma de construir uma sociedade em que 0 art. 54 do Estatuto da Criança e do Adolescente (ECA) que preceitua: "É dever do Estado assegurar à criança e ao adolescente: I - ensino fundamental, obrigatório e gratuito, inclusive para os que a ele não tiveram acesso na idade própria. [...]" (ELIAS, 2010), não seja 
somente mais uma norma legal, mas um instrumento norteador na construção de uma nova sociedade.

Não obstante as mudanças exigidas na sociedade contemporânea que se constrói sob o auspício de uma nova ordem na educação, este artigo trará a lume o fato de que a educação no Brasil cingiu-se de complexidade especialmente, posterior a promulgação da Constituição Federal de 1988, que trouxe uma visão humanizada a toda a sociedade e adentrou os portões das escolas.

Será, portanto apontado neste artigo que a qualidade do ensino e a construção de uma educação cidadã, constituem temas com importantes focos de discussões, que se fundamentam no ECA, nas novas leis que servem de base para a LDB n. 9394/96 e assim ocorre a definição das Políticas Públicas Educacionais.

\section{POLÍTICAS PÚBLICAS EDUCACIONAIS}

Antes de adentrar no contexto que envolve as Políticas Públicas Educacionais, tem-se o entendimento do que vem a ser Política Pública, que a partir da etimologia da palavra se refere ao desenvolvimento a partir do trabalho do Estado junto à participação do povo nas decisões (OLIVEIRA, 2010).

Sob este entendimento conceitua-se que:

Se "políticas públicas" é tudo aquilo que um governo faz ou deixa de fazer, políticas públicas educacionais é tudo aquilo que um governo faz ou deixa de fazer em educação. Porém, educação é um conceito muito amplo para se tratar das políticas educacionais. Isso quer dizer que políticas educacionais é um foco mais específico do tratamento da educação, que em geral se aplica às questões escolares. Em outras palavras, pode-se dizer que políticas públicas educacionais dizem respeito à educação escolar (OLIVEIRA, 2010).

É importante observar que as Políticas Públicas Educacionais não apenas se relacionam às questões relacionadas ao acesso de todas as crianças e adolescentes as escolas públicas, mas também, a construção da sociedade que se origina nestas escolas a partir da educação. Neste entendimento, aponta-se que as Políticas Públicas Educacionais influenciam a vida de todas as pessoas. 
No Brasil, com ênfase para a última década a expressão Políticas Públicas ganhou um rol de notoriedade em todos os campos, fala-se de Políticas Públicas para a educação, saúde, cultura, esporte, justiça e assistência social. No entanto, tais políticas nem sempre trazem os resultados esperados, pois somente garantir o acesso a todos estes serviços públicos não significa que estes tenham qualidade e, que efetivamente, os usuários terão seus direitos respeitados (SETUBAL, 2012).

Diante destes aspectos tem-se que as Políticas Públicas se voltam para o enfrentamento dos problemas existentes no cotidiano das escolas, que reduzem a possibilidade de qualidade na educação. No entanto, somente o direcionamento destas para a educação não constitui uma forma de efetivamente auxiliar crianças e adolescentes a um ensino de melhor qualidade, posto que existam outros pontos que também devem ser tratados a partir das Políticas Públicas, como os problemas de fome, drogas e a própria violência que vem se instalando nas escolas em todo o Brasil (QUADROS, 2008).

Quando se fala em Políticas Públicas na educação a abordagem trata-se da articulação de projetos que envolvem o Estado e a sociedade, na busca pela construção de uma educação mais inclusiva e de melhor qualidade, ou seja, que resgate a construção da cidadania (GIRON, 2008).

Tem-se que o sistema educativo adotado e as Políticas Públicas direcionadas para a educação, são elementos que demonstram a preocupação do país com o seu futuro, pois somente, o ensino público gratuito, inclusivo e de qualidade pode construir uma sociedade em que as diferenças socioculturais e socioeconômicas não são tão díspares (FREIRE, 1998).

Neste sentido, tem-se que as Políticas Públicas Educacionais estão diretamente ligadas a qualidade da educação e, consequentemente, a construção de uma nova ordem social, em que a cidadania seja construída primeiramente nas famílias e, posteriormente, nas escolas e na sociedade.

\section{EDUCAÇÃO PÚBLICA NO BRASIL: Uma História de Encontros e Desencantos}

A escola pública brasileira vem demonstrando, especialmente, nas últimas décadas um processo de desenvolvimento no contexto organizacional 
e de gestão, partindo do princípio que a democracia gera qualidade e oportunidade a todos também no âmbito escolar. Porém, a educação pública necessita mais do que oferecer escolas, mas é imprescindível ter docentes conscientes de seu papel educacional, tanto quanto social, bem como sejam oferecidas as crianças oportunidades de aprendizagem a partir da construção de conhecimento ( BOLZANO, 2004).

A luta por uma escola cidadã no Brasil é envolvida por uma história de encontros e desencantos em que nem sempre o foco dos projetos é a qualidade da educação e a construção da cidadania, isto é:

\begin{abstract}
Ao evidenciar um conjunto de concepções, práticas e estruturas inovadoras, a experiência da escola cidadã aponta possibilidades de uma educação com qualidade social, não redutora à dinâmica mercantil. $O$ desenvolvimento de uma cultura participativa, de uma inquietação pedagógica com a não-aprendizagem, da busca dos aportes teóricos da ciência da educação, legitima a idéia de que a não-aprendizagem é uma disfunção da escola e que a reprovação e a evasão são mecanismos de exclusão daqueles setores sociais que mais necessitam da escola pública. Isso levou à convicção da necessidade de reinventar a escola, de redesenhá-la de acordo com novas concepções. Os avanços na formação em serviço evidenciaram aos educadores que a estrutura convencional da escola está direcionada para transmissão, para o treinamento e para a repetição, tendendo a neutralizar as novas proposições pedagógicas, no máximo transformando-as em modismos fugazes. Por isso, embora essenciais, não bastam apenas mudanças metodológicas, novidades teóricas, a adesão aos princípios de uma escola inclusiva, democrática, com práticas avaliativas voltadas ao sucesso do educando, é indispensável ainda a superação da estrutura tayloristafordista, redefinindo os espaços, os tempos e os modelos de trabalho escolar (AZEVEDO, 2007).
\end{abstract}

Neste sentido, se observam que as transformações vivenciadas no cenário educacional, especialmente, nas escolas públicas nas últimas décadas, estão diretamente ligadas às mudanças ocorridas nos campos político, social econômico e cultural, que originam uma nova situação nas condições de vida da sociedade, seja no campo social ou econômico ( FURGHESTTI, 2012).

Compreender a necessidade de qualidade na educação e buscar a construção desta qualidade somente ocorre quando a escola cumpre com seu papel social e educacional, pois, quando a escola não cumpre efetivamente seu papel (SAVIANI, 2010). 
Dentre os processos que envolvem o desencanto com a educação pública, tem-se o fato de que:

Crianças de $5^{\underline{a}}$ série que não sabem ler nem escrever, salários baixos para todos os profissionais da escola, equipes desestimuladas, famílias desinteressadas pelo que acontece com seus filhos nas salas de aula, qualidade que deixa a desejar, professores que fingem que ensinam e alunos que fingem que aprendem. O quadro da Educação brasileira (sobretudo a pública) está cada vez mais desanimador. [...] (BENCINI, 2006).

Esta realidade de desencanto com a educação brasileira assegura a esta um status de baixa qualidade, seja no contexto de toda a estrutura organizacional e educacional vivenciada, seja nos resultados de desempenho dos estudantes no processo ensino-aprendizagem.

\subsection{A Qualidade da Educação}

A qualidade na educação é elemento complexo devido a sua abrangência e necessidade de ter nas características físicas da escola, nos docentes e na didática de ensino fatores que possibilitem a construção desta qualidade. Isto não significa dizer que nenhuma criança ou adolescente fique fora da sala de aula é, importante que exista qualidade nesta escola básica, oferecida para todos (BOLZANO, 2004).

Com a necessidade de construir uma sociedade mais justa, digna e cidadã as discussões sobre a qualidade da educação se exacerbaram, neste campo tem-se que:

A QUALIDADE do ensino tem sido foco de discussão intensa, especialmente na educação pública. Educadores, dirigentes políticos, mídia e, nos últimos tempos, economistas, empresários, consultores empresariais e técnicos em planejamento têm ocupado boa parte do espaço dos educadores, emitindo receitas, soluções técnicas e, não raro, sugerindo a incompetência dos educadores para produzir soluções que empolguem a qualificação do ensino. Essa invasão de profissionais não identificados ou não envolvidos com as atividades do campo educacional merece uma reflexão. Não se trata aqui de preconizar o monopólio da discussão da educação aos educadores, mas de registrar a intensa penetração ideológica das análises, dos procedimentos e das receitas tecnocráticas à educação (AZEVEDO, 2007). 
A qualidade da educação, especialmente nas escolas públicas não podem ser construídas com base unicamente em políticas quantitativas e privatizadoras, em que a escola particular seja símbolo de eficiência, mas em programas que tenham no resgate da qualidade da escola pública a sua força para alcançar efetivamente um melhor nível educacional.

No Brasil a eficiência das escolas públicas, que poderiam ser traduzidas em qualidade educacional, está intimamente ligada a influencia tecnicista dos americanos e do humanismo republicano. Porém, este humanismo é contraditório, pois não tem por objetivo a formação de cidadãos conscientes de seus direitos e deveres e, sim, de seus direitos, fazendo surgir um paternalismo que oprime a escola a oferece educação e não educação de qualidade(LIBERATI, 2004).

Esta qualidade não é alcançada com uma educação institucionalizada que busca fornecer conhecimento já pronto para que as crianças e os adolescentes continuem a propagação desta sociedade mercantilizada, mas deve buscar a geração e transmissão de valores éticos, morais e cidadãos que efetivamente são construtores de novos conhecimentos e de uma sociedade a luz da cidadania (FURGHESTTI, 2012).

\subsection{A Educação com Base nas Leis Federais}

Embora as Leis 11.114/2005 e 11.274/2006 possam ser compreendidas como instrumentos de avanço na educação, há que se avaliar que as mudanças na educação brasileira iniciaram-se com a LDB 9.394/1996, que constituíram a fonte de ações para um novo olhar das políticas públicas na educação (FURGHESTTI, 2012).

Considera-se importante comentar que a LDB 9.394/1996 foi um marco nos rumos da educação brasileira, consubstanciando em seu art. $2^{\circ}$ que:

Art. $2^{2}$. A educação, dever da família e do Estado, inspirada nos princípios de liberdade e nos ideais de solidariedade humana, tem por finalidade o pleno desenvolvimento do educando, seu preparo para o exercício da cidadania e sua qualificação para o trabalho (BRASIL, 1996). 
A luz desta avaliação tem-se que as leis 11.114/2005 e 11.274/2006, trouxeram mudanças, porém não alteraram na essência a LDB 9.394/1996 devido a sua importância no campo dos avanços para a educação e de leis a ela direcionadas.

Dentre as principais inovações das Leis Federais nำ 11.114/2005 e 11.274/2006, está à garantia de que a educação oferecida a todas as crianças e adolescentes na escola pública brasileira será de qualidade, pois não basta apenas acesso a escola é preciso oportunidade de aprendizagem e construção de conhecimento.

No que concerne à garantia de qualidade da educação, tem-se:

[...] o inciso IX do art. $4^{\circ}$ da LDB dispõe que: "o dever do Estado com a educação escolar pública será efetivado mediante a garantia de: [...] IX - padrões mínimos de qualidade de ensino, definidos como a variedade e quantidade mínimas, por aluno, de insumos indispensáveis ao desenvolvimento do processo ensino/aprendizagem" (AZEVEDO, 2007)

A LDB apresentou que o ensino de qualidade está diretamente ligado a diversos fatores, como a quantidade de alunos em sala de aula; a disponibilidade de recursos materiais, humanos e didáticos em sala de aula e a contextualização da escola com a sociedade, especificamente, com a comunidade em que se encontra inserida (FURGHESTTI, 2012).

\subsection{A Educação e o ECA}

O ECA pode ser considerado um dos grandes marcos do Direito brasileiro, sendo um divisor de águas, não apenas nas questões de proteção aos direitos de menores em confronto com a lei, mas também, nos aspectos que envolvem a educação.

A origem do ECA assim como da LDB de 1996 se alicerçaram em uma necessidade de liberdade e direitos negados nas décadas anteriores:

Nas décadas de 1970 e 1980, durante a ditadura militar pós Al-5 e até pouco depois da sua queda, teve lugar um longo processo de reorganização das forças sociais no Brasil, que levou ao surgimento de diversos movimentos sociais setoriais, à formação de novas organizações político partidárias de base e expressão popular nunca 
vista, como o caso do Partido dos Trabalhadores, e que culmina com o processo da Assembléia Nacional Constituinte (em diante ANC) de 1986, e da promulgação de algumas leis setoriais posteriores, como o Estatuto da Criança e do Adolescente, de 1990, e a própria Lei de Diretrizes e Bases da Educação, de 1996 (MANCILLA, 2006).

Considera-se que tanto o ECA, quanto a LDB foram precedidos por uma mobilização social que continha ânsias sociais, especialmente, no campo da educação e da democracia. Assim, ambas as leis influenciaram grandemente no novo posicionamento da educação pública que intentou o resgate da proteção dos direitos de crianças e adolescentes.

A educação no ECA está priorizada nos arts. 4ำ abaixo apresentado e o 54 anteriormente exposto no presente estudo, sendo que o primeiro trata dos direitos essenciais de crianças e adolescentes e deveres do Estado e de toda a sociedade que deve protegê-los:

Art. 4ํㅡ É dever da família, da comunidade, da sociedade em geral e do poder público assegurar, com absoluta prioridade, a efetivação dos direitos referentes à vida, à saúde, à alimentação, à educação, ao esporte, ao lazer, à profissionalização, à cultura, à dignidade, ao respeito, à liberdade e à convivência familiar e comunitária. (BRASIL, 1990).

Sob o manto protetor da lei, o ECA buscou inovar por possibilitar que crianças e adolescentes a partir do seu direito de inserção a escola e ensino de qualidade, partindo do princípio que um bom nível de educação permite profundas mudanças socioculturais e políticas (OLIVEIRA, 2003).

Falar da educação em relação ao ECA é, antes de mais nada, propagar uma das principais preocupações deste estatuto, pois ele traz em seu bojo a essência do processo ensino-aprendizagem de crianças e adolescentes, enquanto direito social.

\subsection{A Educação a Luz da Constituição Federal}

A Constituição Federal brasileira de 1988, considerada a mais humana de todos os tempos, trouxe em seu bojo abordagens importantes para a educação. Nesta contextualização, o artigo 205 preleciona que: será promovida e incentivada com a colaboração da sociedade, 
visando ao pleno desenvolvimento de pessoas, seu preparo para o exercício da cidadania e sua qualificação para o trabalho (BULOS, 2009).

Não obstante aponta-se que a Constituição Federal (CF) não traz em seu bojo somente o acesso à escola, mas o pleno desenvolvimento das pessoas a partir da educação, o que denota a pertinência de uma educação de qualidade. Sendo que a CF em seu art. 205, VII, menciona a "garantia de padrão de qualidade" do ensino, ou seja, não apenas o acesso de crianças e adolescentes a escola, mas um ensino de qualidade. Garantia está também presente no inciso IX do art. $4^{\circ}$ da LDB.

Ao tratar sobre a educação à luz da Constituição Federal, tem-se que segundo a: "[...] legislação brasileira, o direito à educação engloba os pais, o Estado e a comunidade em geral e os próprios educandos, mas é obrigação do Estado garantir esse direito, inclusive quando o assunto é qualidade. [...]" (CABRAL, 2012).

Em consonância com a Constituição Federal de 1988 a educação pública de qualidade é obrigação do Estado, sendo ainda o acesso ao ensino fundamental obrigatório e gratuito, um direito público subjetivo (BRASIL, 1988).

A Constituição Federal em seu art. 6ำ preceitua:

Art. 6 São direitos sociais a educação, a saúde, a alimentação, o trabalho, a moradia, o lazer, a segurança, a previdência social, a proteção à maternidade e à infância, a assistência aos desamparados, na forma desta Constituição. (Redação dada pela Emenda Constitucional no 64, de 2010) (BRASIL, 2010).

Neste enfoque quando é negado a qualquer criança ou adolescente o seu direito de frequentar uma escola e receber um ensino de qualidade, possibilitando a construção de valores que o levam ao exercício da cidadania, se está negando um direito social amparado na Constituição Federal.

\section{CONSIDERAÇÕES FINAIS}

As discussões sobre o que é qualidade na educação remontam a diversos aspectos, sendo que no decorrer da construção deste artigo, tem-se que esta qualidade origina-se de diversos indicadores: a qualidade da 
estrutura predial, organizacional e humana das escolas, além do aporte metodológico e didático que possibilita aos docentes oferecer um processo ensino-aprendizagem qualitativo.

As Políticas Públicas Educacionais são de extrema importância no que se relaciona a tornar o ensino fundamental público mais qualitativo, em todos os âmbitos formando assim, verdadeiros cidadãos.

O Brasil passou nas décadas de 70 e 80 por um processo de impedimento do crescimento intelectual e escolar. Neste sentido, a Constituição Federal de 1988, o Estatuto da Criança e do Adolescente em 1990 e a LDB 9.394/1996 foram instrumentos da reconstrução de um país efetivamente democrático, em que a educação não apenas torna-se um direito de crianças e adolescentes, mas um dever do Poder Público, família, escola e toda a sociedade.

Considerou-se ainda que as alterações da LDB 9.394/1996 nos anos de 2005 e 2006, não modificaram a sua essência que constitui o alicerce de uma educação pública de qualidade efetivamente formadora de cidadãos aptos a construir uma nova sociedade.

Por fim, aponta-se que a Constituição Federal de 1988 diversa da maioria das constituições e instrumentos internacionais, não apenas tratou da educação, mas fez menção expressa a necessidade de que se ofereça uma educação pública de qualidade e acessível a todos. Sob o manto protetor deste instrumento, tornou-se assim, a educação de qualidade, um direito social.

\section{REFERÊNCIAS}

AZEVEDO, José Clovis de. Educação pública: o desafio da qualidade. Estud. av. v.21. n.60. São Paulo. May/Aug. 2007.

BENCINI, Roberta; MORAES, Trajano de; MINAMI, Thiago. O desafio da qualidade não dá mais para esperar: ou o Brasil coloca a Educação no topo das prioridades ou estará condenado ao subdesenvolvimento. A boa notícia é que a situação tem jeito se a sociedade agir já. Nova Escola. Ano XXI. N.1996. Out. de 2006.

BOLZANO, Sonia Maria Nogueira. Do direito ao ensino de qualidade ao direito de aprender com qualidade - o desafio da nova década. In: LIBERTI, Wilson 
Donizeti. Direito à educação: uma questão de justiça. São Paulo: Malheiros, 2004, p.122.

BRASIL. Lei no 11.114 de 16 de maio de 2005. Disponível em: <http://www.planalto.gov.br/ccivil_03/_Ato2004-2006/2005/Lei/L11114.htm>. Acesso em: 25 Abr. 2013.

BRASIL. Lei no 11.274 de 06 de fevereiro de 2006. Disponível em: <http://www.planalto.gov.br/ccivil_03/_Ato2004-2006/2006/Lei/L11274.htm>. Acesso em: 25 Abr. 2013.

BRASIL. Constituição da República Federativa do Brasil de 05 de outubro de 1988. Disponível em: <http://www.planalto.gov.br/ccivil_03/constituicao/ constituicao.htm>. Acesso em: 25 Abr. 2013.

BRASIL. Lei no 9.394, de 20 de dezembro de 1996. Disponível em: $<$ http://portal.mec.gov.br/seed/arquivos/pdf/tvescola/leis/lein9394.pdf>. Acesso em: 26 Abr. 2013.

BULOS, Uadi Lammêgo. Constituição federal anotada. 9. ed. rev. e atual. até a EC n.57/2008. São Paulo: Saraiva, 2009.

CABRAL, Karina Melissa; DI GIORGI, Cristiano Amaral Garboggini. O direito à qualidade da educação básica no Brasil: uma análise da legislação pertinente e das definições pedagógicas necessárias para uma demanda judicial.

Educação. Porto Alegre. v.35. n.1. jan./abr. 2012.

ELIAS, Roberto João. Comentários ao Estatuto da Criança e do

Adolescente: Lei n. 8.069, de 13 de julho de 1990. 4. ed. São Paulo: Saraiva, 2010.

FREIRE, Paulo. Pedagogia da autonomia: saberes necessários à prática educativa. São Paulo: Paz e Terra, 1998.

FURGHESTTI, Mara Luciane da Silva; GRECO, Maria Terêsa Cabral;

CARDOSO, Rosinete Costa Fernandes. Ensino fundamental de nove anos: os impactos das políticas públicas para a alfabetização com letramento. IX

ANPED Sul Seminário de Pesquisa em Educação da Região Sul. 2012.

GIRON, Graziela Rossetto. Políticas públicas, educação e neoliberalismo: o que isso tem a ver com a cidadania. Revista de Educação. PUC-Campinas. Campinas. n.24. jun. 2008.

LIBERATI, Wilson Donizetti. Conteúdo material do direito à educação escolar. In: LIBERTI, Wilson Donizeti. Direito à educação: uma questão de justiça. São Paulo: Malheiros, 2004.

MANCILLA, Claudio Andrés Barria. ECA, LDB e educação popular: perspectivas diversas para diversos fins. Educação Popular. n.06. 2006. 
OLIVEIRA, Adão Francisco de. Políticas públicas educacionais: conceito e contextualização numa perspectiva didática. In: OLIVEIRA, Adão Francisco de. Fronteiras da educação: tecnologias e políticas. Goiânia-Goiás: PUC Goiás, 2010.

OLIVEIRA, Antônio Carlos de; AMERICANO, Naura dos Santos. Crianças e adolescentes em situação de rua: a difícil Arte de cuidar. Rio de Janeiro: Nova, 2003.

QUADROS, Neli Helena Bender de. Políticas públicas voltadas para a qualidade da educação no ensino fundamental: inquietudes e provocações a partir do plano de desenvolvimento da educação. [Dissertação de Mestrado em Educação]. Passo Fundo-RS: Faculdade de Educação da Universidade de Passo Fundo, 2008.

SAVIANI, Demerval. História das ideais pedagógicas no Brasil. CampinasSP: Autores Associados, 2010.

SETUBAL, Maria Alice. Com a palavra... Consulex. Ano XVI. N.382. 15 de Dezembro de 2012.

\footnotetext{
'Pós-graduada em Direito Público pela UCDB; Pós-graduanda em Didática do Ensino Superior pela UNIC Rondonópolis; Pós-graduanda em Gestão Pública Municipal pela UFMT; Graduada em Direito pela UEMS; Coordenadora do Núcleo de Prática Jurídica da UNIC; Professora Universitária-UNIC Rondonópolis; Advogada OAB № 14.055-B.

${ }^{2}$ Mestrando em Educação-UFMT Cuiabá; Especialista em Direito Público Material (Damásio de Jesus), Didática e Metodologia do Ensino Superior (Anhanguera); Tecnologia Contemporânea e Novas Práticas Educacionais (Faculdade João CalvinoBA). Graduado em Direito (Anhanguera) e Licenciatura em Matemática (UFMT). Técnico do Ministério Público de Mato Grosso; Professor UNEMAT.
}

RECEBIDO EM: julho/2014

APROVADO EM: agosto/2014 